\title{
Measurement of peak rates of left ventricular wall movement in man Comparison of echocardiography with angiography
}

\author{
D. G. Gibson and D. J. Brown
}

From the Cardiac Department, Brompton Hospital, London, and the Medical Computer Centre, Westminster Hospital, London

Estimates of peak systolic and diastolic rates of left ventricular wall movement were made in 23 patients by echocardiography and angiocardiography. Echocardiographic measurements were calculated as the rate of change of the transverse left ventricular dimension, derived continuously throughout the cardiac cycle. These were compared with similar plots of transverse left ventricular diameter, in the same patients, derived from digitized cineangiograms taken within 10 minutes of echocardiograms. The results indicate close correlation between the two methods, and suggest that either can be used to measure peak rates of left ventricular wall movements in patients with heart disease.

Identification of echoes arising from the interventricular septum and posterior wall of the left ventricle has proved to be a significant advance in the study of cardiac function by allowing the transverse diameter of the left ventricle to be measured at end-systole and end-diastole (Chapelle and Mensch, 1969; Feigenbaum et al., 1969). More recently, it has been possible to derive this dimension continuously throughout the cardiac cycle (Gibson and Brown, 1973; Griffith and Henry, 1973), using simple digitizing techniques, so that peak rates of wall movement can also be estimated. In the present study, we have compared such measurements with those based on digitized cineangiograms in order to study the relation between the two methods, and have examined potential limitations of echocardiography in estimating left ventricular cavity size from a single dimension.

\section{Subjects and methods}

Studies were made of 23 patients with valvular heart disease or cardiomyopathy. Clinical details are given in Table $\mathrm{I}$. They were a selected group in so far as all of them required left and right heart catheterization and left ventriculography for diagnostic purposes, and patients with ischaemic heart disease were deliberately excluded. In all of them it was possible to record technically satisfactory echocardiograms of the left ventricular cavity.

Received 23 December 1974.

\section{Echocardiograms}

In order to reduce the time interval between the two investigations, echocardiograms were performed at cardiac catheterization using techniques that have previously been described (Gibson, 1973). Clear, continuous echoes were obtained from the posterior surface of the septum and the endocardium of the posterior wall of the left ventricle, which were distinguished from those originating from the mitral valve apparatus. Septal movement was classified as being normal if the dominant movement during ventricular systole was in a posterior direction, and reversed if in an anterior direction. In all patients, at least two records were made, with removal of the transducer and re-identification of the landmarks between the first and the second.

\section{Angiograms}

Patients were studied fasting and were premedicated with $200 \mathrm{mg}$ amylobarbitone, given orally one hour before the start of the procedure. Two patients (Cases II and 20) were investigated under general, and the remainder under local, anaesthesia. Right heart catheterization was performed in all patients, and an estimate of the cardiac output made by the direct Fick method, using an assumed basal oxygen uptake. Left ventriculography was performed 5 to 10 minutes after echocardiography, with the patient in either the posteroanterior or the right anterior oblique position. An injection of 40 to $50 \mathrm{ml} 70$ per cent Triosil was made into the left ventricle at a flow rate of $25 \mathrm{ml} / \mathrm{s}$, and cine film exposed at approximately 50 frames/s. An electrocardiogram was recorded throughout, with the timing of cine frames 
TABLE I Clinical details

\begin{tabular}{|c|c|c|c|c|c|c|c|}
\hline $\begin{array}{l}\text { Case } \\
\text { no. }\end{array}$ & $\begin{array}{l}\text { Age } \\
(y r)\end{array}$ & Sex & Diagnosis & $\begin{array}{l}\text { Surface } \\
\text { area }\left(m^{2}\right)\end{array}$ & Rhythm & $\begin{array}{l}\text { Cardiac } \\
\text { index } \\
(l / m i n \\
\left.\text { per } m^{2}\right)\end{array}$ & $\begin{array}{l}\text { Ejection } \\
\text { fraction }\end{array}$ \\
\hline $\mathbf{I}$ & 38 & $\mathbf{M}$ & $\mathrm{AR}, \mathrm{MR}$ & 1.9 & SR & 1.7 & 0.31 \\
\hline 2 & 25 & $\mathbf{M}$ & ASD (secundum) & 1.6 & SR & 2.2 & 0.63 \\
\hline 3 & 39 & $\mathbf{F}$ & MS, MR & 1.5 & AF & 1.6 & 0.38 \\
\hline 4 & 36 & $\mathrm{~F}$ & MS, MR & 1.6 & SR & 2.9 & 0.69 \\
\hline 5 & 42 & $\mathbf{M}$ & MS, MR & 1.7 & AF & 0.9 & 0.22 \\
\hline 6 & 67 & $\mathbf{M}$ & MS, MR & 1.9 & $\mathrm{AF}$ & 1.8 & 0.52 \\
\hline 7 & 58 & $\mathbf{M}$ & MS (homograft) & 1.8 & AF & I.I & 0.40 \\
\hline 8 & 67 & M & MR & 1.6 & AF & 1.9 & $0.5 \mathrm{I}$ \\
\hline 9 & 23 & M & MS, MR, TR & 1.5 & AF & 1.7 & 0.39 \\
\hline 10 & 27 & $\mathbf{M}$ & $\mathrm{MR}, \mathrm{AR}$ & 1.9 & SR & 2.4 & 0.80 \\
\hline II* & 15 & $\mathbf{F}$ & MR & 1.5 & SR & 1.3 & $0.5 \mathrm{I}$ \\
\hline 12 & 51 & $\mathbf{M}$ & MS (homograft) & 1.7 & SR & 2.2 & $0.2 \mathrm{I}$ \\
\hline 13 & 68 & $\mathbf{M}$ & MR & 2.0 & SR & 1.2 & 0.79 \\
\hline 14 & 23 & $\mathbf{M}$ & HOCM & 1.5 & SR & 1.6 & 0.63 \\
\hline 15 & 60 & $\mathbf{F}$ & MR & 1.5 & SR & 2.3 & 0.79 \\
\hline 16 & 47 & $\bar{M}$ & Cardiomyopathy & 1.8 & SR & 1.8 & $0.3 \mathrm{I}$ \\
\hline 17 & 38 & $\mathbf{M}$ & AR & 1.9 & SR & 2.2 & 0.34 \\
\hline 18 & 61 & $\mathbf{F}$ & M. Starr & 1.8 & AF & 3.5 & 0.40 \\
\hline 19 & 20 & $\mathbf{F}$ & $\mathrm{AR}, \mathrm{MS}, \mathrm{MR}$ & 1.5 & SR & 2.2 & 0.60 \\
\hline $20^{\star}$ & 5 & $\mathbf{M}$ & VSD, PDA & 0.73 & SR & 5.0 & 0.72 \\
\hline $2 \mathbf{I}$ & 51 & $\mathbf{M}$ & MS & 1.9 & AF & 1.3 & 0.31 \\
\hline 22 & 52 & $\mathbf{F}$ & M. Starr, TR & I. 6 & $\mathrm{AF}$ & 1.3 & 0.36 \\
\hline 23 & 62 & $\mathbf{M}$ & MR & 1.6 & SR & 3.1 & 0.75 \\
\hline
\end{tabular}

* Studied under general anaesthetic.

$A=$ Aortic; $M=$ Mitral; $T=$ Tricuspid; $R=$ Regurgitation: $S=$ Stenosis; HOCM = Hypertrophic obstructive cardiomyopathy; Starr $=$ Starr-Edwards prosthesis; $S R=$ Sinus rhythm; $\mathrm{AF}=$ Atrial fibrillation; $A S D=$ Atrial septal defect; $V S D=$ Ventricular septal defect; $P D A=$ Persistent ductus arteriosus.

superimposed on it, so the film speed could be measured exactly. Calibration was performed using either a grid at midchest level, or from measurement of the diameter of the catheter on the film itself. Ectopic and postectopic beats were not studied.

\section{Radiographic techniques}

The $x$-ray tube, mounted above the patient, was a Siemen's RG $150 / 100$ working at $200 \mathrm{~mA}$ and $3 \mathrm{~ms}$. A Siemen's Sirecon Duplex (H) intensifier was used, with a caesium iodide input screen. The overall resolution of the system, using cine film with a $25 \mathrm{~cm}$ field was better than 2.4 line pairs $/ \mathrm{mm}$ at the 4 per cent contrast level.

\section{Digitization}

Echocardiograms were digitized using the technique previously described (Gibson and Brown, 1973), with a DMAC digitizing table interfaced with an IBM computer. Strings of co-ordinates were generated for 50 to 70 points on the septal and posterior wall echoes, from which the left ventricular dimension was derived by subtraction, after an interpolation procedure. Calibration data included intervals representing $\mathrm{r} \mathrm{cm}, 0.5 \mathrm{~s}$ and the $Q Q$ interval of the beat being studied, together with a correction for lack of rectilinearity of the echocardiogram on the digitizing table. This information was stored on magnetic tape and used for further analysis.

Cineangiograms were digitized in a similar manner. Successive frames of the beat to be studied were projected on to the digitizing table, starting at end-diastole, and the perimeter of the ventricular cavity, as outlined by dye, was traced with a cursor, starting from the aortic root. The co-ordinates of approximately 50 points on each frame, together with a reference point either in the thorax or on the border of the cine frame, were recorded and stored on magnetic tape for further analysis.

\section{Analysis of data}

Echocardiograms were analysed as previously described. Plots were made of left ventricular dimension (D), rate of change of dimension $(\mathrm{dD} / \mathrm{dt})$, and normalized rate of change of dimension ( $/ / \mathrm{D} . \mathrm{dD} / \mathrm{dt}$ ) from which peak systolic and early diastolic rates were derived.

The method used to analyse cineangiograms is illustrated in Fig. I-4. From stored information, the cavity outlines of the beat being studied were plotted superimposed on one another. Those from the start of the beat to the one with the smallest area were taken as systolic, 


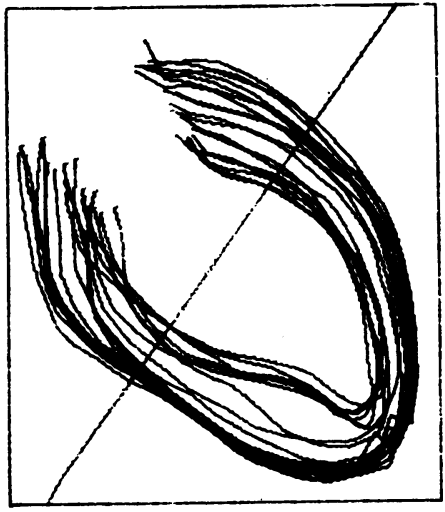

DIASTOLE

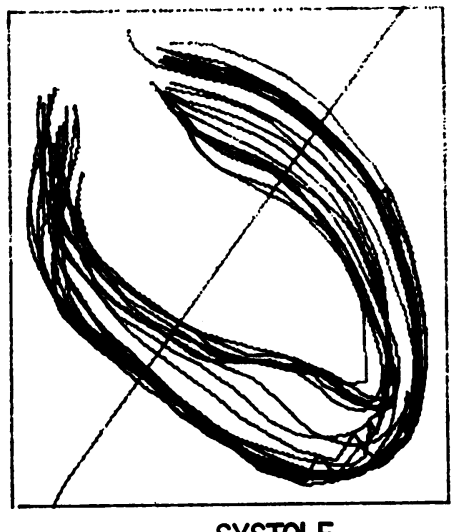

SYSTOLE

FIG. I Digitized cineangiogram from Case 10. Successive outlines of the left ventricular cavity at $20 \mathrm{~ms}$ intervals throughout systole and diastole are shown, together with the position of the dimensions along which the measurements were made.

and the remainder as diastolic, as cavity size was increasing again. Additional plots were made of cavity area and its rate of change with time. Cavity volume was estimated from area, and ejection fraction derived in the usual way as stroke volume divided by end-diastolic volume. For each beat, a transverse diameter, analogous to the path of the ultrasound beam was defined relative to the cavity outlines, which were displayed on a Ferranti MD4 VDU, by manually adjusting the position of a cursor until it passed below the region representing the mitral valve, and perpendicular to both the long axis of the cavity and the walls of the left ventricle. The magnitude of the dimension thus defined was derived from the stored data and plotted together with its rate of change.

\section{Frequency response}

The frequency response of the echocardiograph is linear to $500 \mathrm{~Hz}$. That of the digitizing system, using no

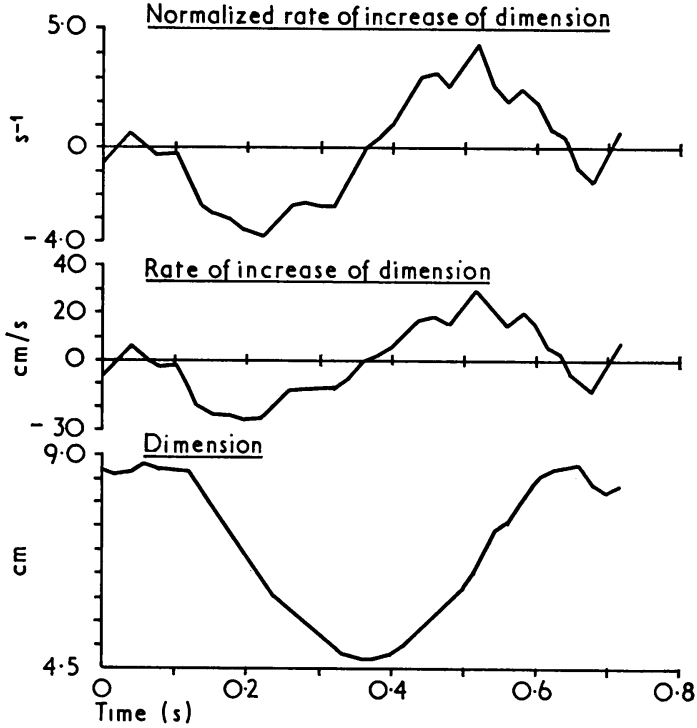

FIG. 2 Measurements of left ventricular dimension and its rate of change throughout a single cardiac cycle in Case 10.

smoothing, was investigated, using an impulse as input and performing a Fourier analysis on the output. This showed a 5 per cent reduction in amplitude below predicted at the 5oth harmonic, the fundamental corresponding to a heart rate of $100 /$ minute. Using this system, records of to representative patients were analysed, and no significant information was found above the tenth harmonic. Throughout the present study, therefore, a three point moving average filter was used, which was associated with a 5 per cent reduction in output below the predicted value at $10 \mathrm{~Hz}$.

\section{Statistical analysis}

The reproducibility of the angiographic method was investigated in detail, and expressed as the root mean square (RMS) differences between duplicate determinations of peak rates of wall movement under different circumstances in the same subject.

The effects of differences between separate attempts to position the cursor using the criteria defined above were examined by comparing measurements made on the same beat on different occasions. The sensitivity of these measurements to cursor position was assessed by observing the effect of rotating it by $20^{\circ}$ on either side of its original position, so that a total range of $40^{\circ}$ could be studied. Finally, the difference between measurements made on successive beats was assessed. These results are summarized in Table 4, together with RMS differences between estimates of peak rates of wall movement from separate echocardiograms in the same patient.

Linear regression between end-diastolic dimensions, and between peak systolic and diastolic rates of wall 

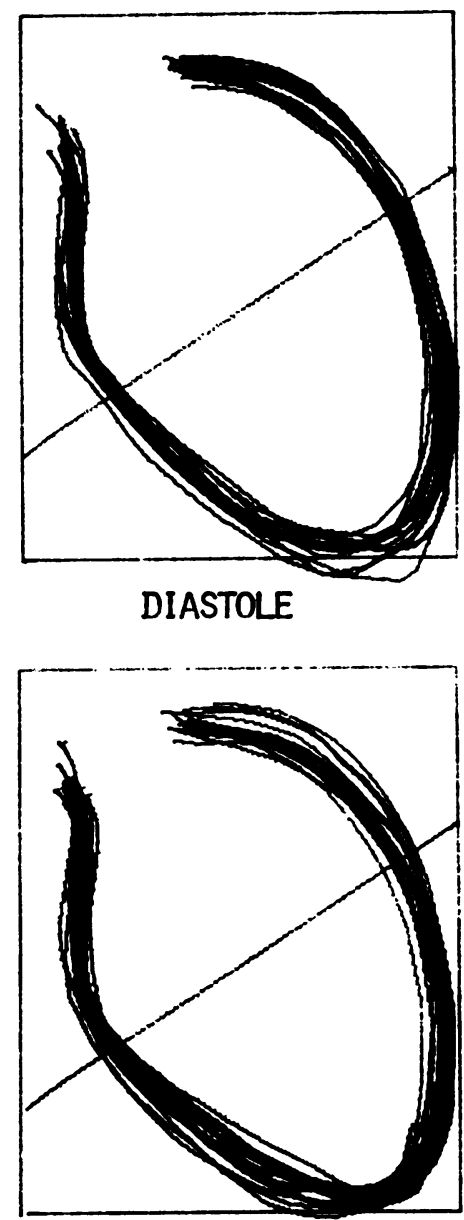

SYSTOLE

FIG. 3 Digitized cineangiogram from Case 16.

movement estimated by echo and angiographic methods was performed by the method of least squares.

\section{Results}

\section{Echocardiographic}

In the group of patients studied, the end-diastolic dimension ranged from 3.4 to $8.6 \mathrm{~cm}$. Septal movement was normal in 18 patients and reversed in 5, associated with right ventricular overload in 2 (Diamond et al., 197r), mitral Starr-Edwards prostheses in 2 (Miller, Gibson, and Stephens, 1973), and mitral valve disease in I. These results are given in detail in Table 2. Peak rates of change of dimension in systole lay between 3.3 and $17 \mathrm{~cm} / \mathrm{s}$, or $0.5-3.8 \mathrm{~s}^{-1}$ when normalized, and the RMS difference between duplicate determinations of
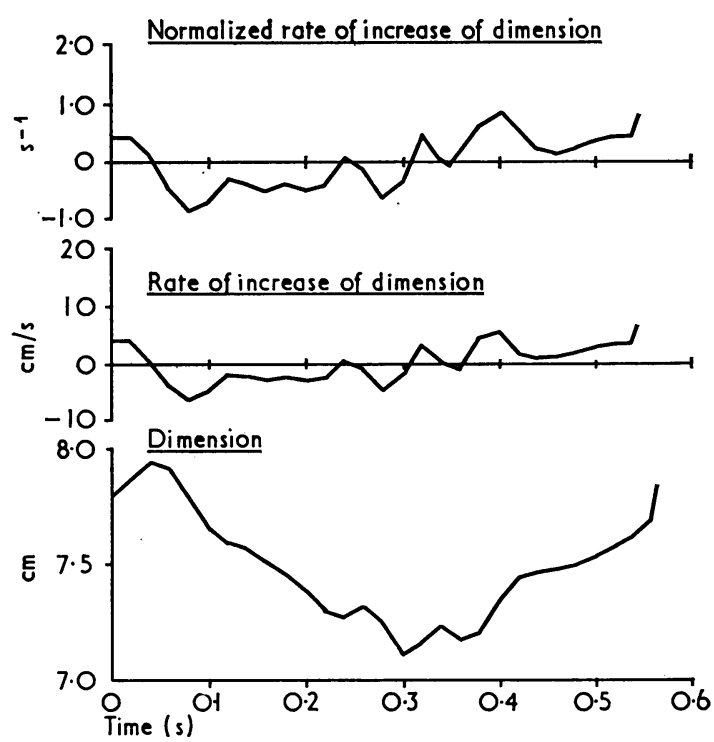

FIG. 4 Measurements of left ventricular dimension and its rate of change, from Case 16.

systolic wall movement on different echocardiograms was $1.5 \mathrm{~cm} \mathrm{~s}^{-1}$ or $0.34 \mathrm{~s}^{-1}$ from normalized values. The peak rate of diastolic wall movement lay between 3.0 and $24 \mathrm{~cm} / \mathrm{s}$, or 0.7 and $6.0 \mathrm{~s}^{-1}$ when expressed in terms of unit length. The RMS differences between determinations from different echocardiograms in the same patient were $2.5 \mathrm{~cm} \mathrm{~s}^{-1}$ or $0.80 \mathrm{~s}^{-1}$.

\section{Angiographic}

Examples of the method of display used for the digitization of left ventricular cineangiograms are shown in Fig. I and 3. Successive outlines of the left ventricular cavity from a single beat are shown, with the position of the dimension along which measurements were made. Peak rates of systolic wall movement lay between 4 and $25 \mathrm{~cm} \mathrm{~s}^{-1}$, or 0.5 and $3.8 \mathrm{~s}^{-1}$, and peak diastolic rates between 3 and $30 \mathrm{~cm} \mathrm{~s}^{-1}$, or 0.8 and $8 \mathrm{~s}^{-1}$ (Table 3). Figures for the reproducibility of measurement of normalized shortening rate under different circumstances are given in detail in Table 4. The RMS difference in peak rate of change of dimension between two independent attempts to position the cursor was $0.23 \mathrm{~s}^{-1}$ in systole and $0.22 \mathrm{~s}^{-1}$ in diastole. The corresponding figures for rotation of the cursor by $20^{\circ}$ and $40^{\circ}$ were 0.26 and $0.28 \mathrm{~s}^{-1}$ in systole and 0.45 and $0.55 \mathrm{~s}^{-1}$ in diastole. The RMS difference between measurements made from separate beats in the same cineangiogram was $0.35 \mathrm{~s}^{-1}$ in systole and $0.7 \mathrm{~s}^{-1}$ in diastole. 
TABLE 2 Echocardiographic data

\begin{tabular}{|c|c|c|c|c|c|c|}
\hline \multirow[t]{2}{*}{$\begin{array}{l}\text { Case } \\
\text { No. }\end{array}$} & \multirow{2}{*}{$\begin{array}{l}\text { End- } \\
\text { diastolic } \\
\text { dimension } \\
(\mathrm{cm})\end{array}$} & \multirow[t]{2}{*}{$\begin{array}{l}\text { Septal } \\
\text { movement }\end{array}$} & \multicolumn{2}{|c|}{$\begin{array}{l}\text { Peak rate of change of } \\
\text { dimension }\left(\mathrm{cm} \mathrm{s}^{-1}\right)\end{array}$} & \multicolumn{2}{|c|}{$\begin{array}{l}\text { Normalized peak rate of } \\
\text { change of dimension }\left(s^{-1}\right)\end{array}$} \\
\hline & & & Systolic & Diastolic & Systolic & Diastolic \\
\hline I & 8.6 & $\mathbf{N}$ & 5 & 8.5 & 0.7 & I.I \\
\hline 2 & 3.6 & $\mathbf{R}$ & 7 & 19 & 1.5 & 4.5 \\
\hline 3 & 5.3 & $\mathbf{N}$ & 6 & 5 & 1.2 & 1.2 \\
\hline 4 & 5.6 & $\mathbf{N}$ & 5 & 12 & 1.0 & 2.8 \\
\hline 5 & 6.1 & $\mathbf{N}$ & 3.5 & 5.5 & 0.9 & 1.0 \\
\hline 6 & 5.4 & $\mathbf{N}$ & 4.5 & 15 & 1.3 & 3.0 \\
\hline 7 & 3.8 & $\mathbf{N}$ & 8.5 & 7.5 & 2.5 & 2.5 \\
\hline 8 & 5.7 & $\mathbf{N}$ & 9 & 18 & 1.7 & 4.0 \\
\hline 9 & 5.0 & $\mathbf{N}$ & 6.5 & 7.5 & 1.8 & 2.8 \\
\hline ro & 6.9 & $\mathbf{N}$ & 17 & 17 & 2.4 & 2.7 \\
\hline II & 5.6 & $\mathbf{N}$ & I0 & 19 & 2.0 & 3.9 \\
\hline 12 & 6.1 & $\mathbf{R}$ & 3.5 & 3.5 & 0.8 & 1.0 \\
\hline 13 & 6.2 & $\mathbf{N}$ & 12 & 24 & 2.8 & 6.0 \\
\hline 14 & 3.4 & $\mathbf{N}$ & 7 & 13 & 3.0 & 4.7 \\
\hline 15 & 7.4 & $\mathbf{N}$ & 9 & 20 & 1.8 & 3.0 \\
\hline 16 & 6.0 & $\mathbf{N}$ & 3 & 3.5 & 0.5 & 1.0 \\
\hline 17 & 9.0 & $\mathbf{N}$ & 5 & 8 & 0.8 & I. 4 \\
\hline 18 & 5.0 & $\mathbf{R}$ & II & 19 & 2.8 & 4.0 \\
\hline 19 & 6.0 & $\mathbf{N}$ & 7 & 14 & 2.3 & 3.5 \\
\hline 20 & 3.7 & $\mathbf{R}$ & 12 & 14 & 3.8 & 5.5 \\
\hline 21 & 7.1 & $\mathbf{N}$ & 4 & 3 & I. 0 & 0.7 \\
\hline 22 & 5.0 & $\mathbf{R}$ & 4 & I0 & 0.9 & 1.5 \\
\hline 23 & 6.2 & $\mathbf{N}$ & 13 & 22 & 2.8 & 4.0 \\
\hline
\end{tabular}

$\mathbf{N}=$ Normal $; \mathbf{R}=$ Reversed.

TABLE 3 Angiocardiographic data

\begin{tabular}{|c|c|c|c|c|c|}
\hline \multirow[t]{2}{*}{$\begin{array}{l}\text { Case } \\
\text { No. }\end{array}$} & \multirow[t]{2}{*}{$\begin{array}{l}\text { End-diastolic } \\
\text { dimension }(\mathrm{cm})\end{array}$} & \multicolumn{2}{|c|}{$\begin{array}{l}\text { Peak rate of change of } \\
\text { dimension }\left(\mathrm{cm} \mathrm{s}^{-1}\right)\end{array}$} & \multicolumn{2}{|c|}{$\begin{array}{l}\text { Normalized peak rate of } \\
\text { change of dimension }\left(s^{-1}\right)\end{array}$} \\
\hline & & Systolic & Diastolic & Systolic & Diastolic \\
\hline I & 8.6 & 7 & 8 & 1.0 & I.I \\
\hline 2 & 5.2 & ro & 12 & 1.4 & 3.0 \\
\hline 3 & 5.3 & 6 & 5 & 1.3 & 1.2 \\
\hline 4 & 5.5 & 9 & 17 & I. 4 & 4.0 \\
\hline 5 & 6.4 & 4 & 3 & 0.55 & I.I \\
\hline 6 & 6.5 & 7 & 20 & 1.6 & 3.0 \\
\hline 7 & 5.0 & 12 & 12 & 2.0 & 2.4 \\
\hline 8 & 6.5 & 8 & I8 & 1.7 & 3.2 \\
\hline 9 & 6.1 & Io & 12 & 2.0 & 2.0 \\
\hline I0 & 8.7 & 25 & 30 & 3.8 & 4.0 \\
\hline I I & 6.3 & IO & 22 & 1.8 & 4.8 \\
\hline 12 & 6.3 & 4 & 8 & 0.9 & 0.8 \\
\hline 13 & 6.5 & 18 & 30 & 2.5 & 8.0 \\
\hline 14 & 4.0 & I0 & 10 & 3.3 & 3.3 \\
\hline 15 & 7.5 & I7 & 28 & 2.I & 4.7 \\
\hline 16 & 7.8 & 4 & 6 & 0.8 & 0.8 \\
\hline 17 & 8.9 & 8 & Io & 0.5 & I. 4 \\
\hline 18 & 5.6 & 14 & 23 & 2.7 & 5.0 \\
\hline 19 & 7.3 & 14 & 20 & 2.4 & 3.5 \\
\hline 20 & $3 \cdot 3$ & I0 & 14 & 3.3 & 6.2 \\
\hline 21 & 7.0 & 6 & 8 & 0.9 & I.I \\
\hline 22 & 5.5 & 5 & I0 & 0.95 & 1.5 \\
\hline 23 & 7.5 & 12 & 20 & 3.5 & 3.5 \\
\hline
\end{tabular}


TABLE 4 Reproducibility of normalized measurements

\begin{tabular}{lll}
\hline & Systole $\left(s^{-1}\right)$ & Diastole $\left(s^{-1}\right)$ \\
\hline Between beats, angiogram & 0.35 & 0.70 \\
Same beat, angiogram & & \\
Repeat determination & 0.23 & 0.22 \\
Rotate by $\pm 20^{\circ}$ & 0.26 & 0.45 \\
Rotate by $40^{\circ}$ & 0.28 & 0.55 \\
Between echocardiograms & 0.34 & 0.80 \\
& & \\
\hline
\end{tabular}

Root mean square differences between pairs of determinations.

\section{Comparison of methods}

Estimates of end-diastolic dimension were similar by the two techniques and were related by the regression equation:

$\mathrm{ECHO}=0.89$ (ANGIO) $+0.04 \mathrm{~cm}$.

Standard error of the estimate $0.65 \mathrm{~cm}, \mathrm{r}=0.90$.

Comparison of estimates of peak rates of wall movement by the two techniques are shown in Fig. 5 and 6 . The corresponding regression equations were:-

$\mathrm{ECHO}=0.62$ (ANGIO) $+\mathrm{r} .3 \mathrm{~cm} \mathrm{~s}^{-1}$, during systole (Fig. 5).

Standard error of the estimate $2.1 \mathrm{~cm} \mathrm{~s}^{-1}, \mathrm{r}=0.84$

$\mathrm{ECHO}=0.68(\mathrm{ANGIO})+2.3 \mathrm{~cm} \mathrm{~s}^{-1}$, during diastole (Fig. 6).

Standard error of the estimate $3.4 \mathrm{~cm} \mathrm{~s}^{-1}, \mathrm{r}=0.85$.

The corresponding equations for normalized data were:

$\mathrm{ECHO}=0.84(\mathrm{ANGIO})+0.24 \mathrm{~s}^{-1}$, in systole

Standard error of the estimate $0.44 \mathrm{~s}^{-1}, \mathrm{r}=0.87$, and

$\mathrm{ECHO}=0.76$ (ANGIO) $+0.62 \mathrm{~s}^{-1}$, in diastole.

Standard error of the estimate $0.85 \mathrm{~s}^{-1}, \mathrm{r}=0.86$.

All these results are statistically significant at the O.I per cent level.

\section{Discussion}

Using a simple digitizing technique, a continuous plot of the distance between the interventricular septum and the posterior wall of the left ventricle can be derived from a standard echocardiogram. Its first differential with respect to time gives information about the pattern of left ventricular ejection and filling which cannot easily be obtained in other ways. Indirect confirmation that the method may be of clinical value has already been provided by demonstrating a relation between the pattern of left ventricular filling and the presence of stenotic or regurgitant mitral valve disease (Gibson and Brown, 1973), and in order to provide more rigorous validation, the current method of measur-

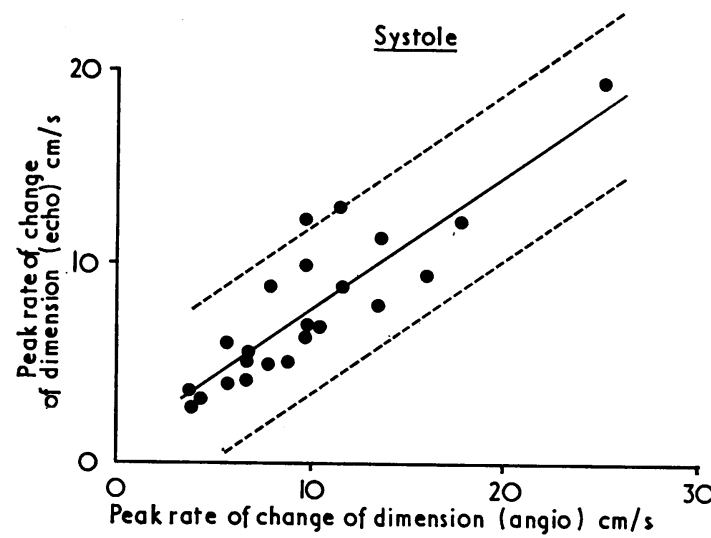

FIG. 5 Relation between estimates of peak systolic rates of left ventricular wall movement made by echocardiography and angiography. The regression line is shown, with limits set at 2 standard errors of the estimate.

ing peak rates of wall movement from cineangiograms was employed. Normalized rates of change referring to unit length have also been calculated as well as absolute values, since they are sensitive measures of left ventricular systolic function, measured either by angiography (Gault, Ross, and Braunwald, 1968) or echocardiography (unpublished observations), and of left ventricular filling pattern, and since their use avoids difficulties in scaling between the two techniques. The maximum frequency

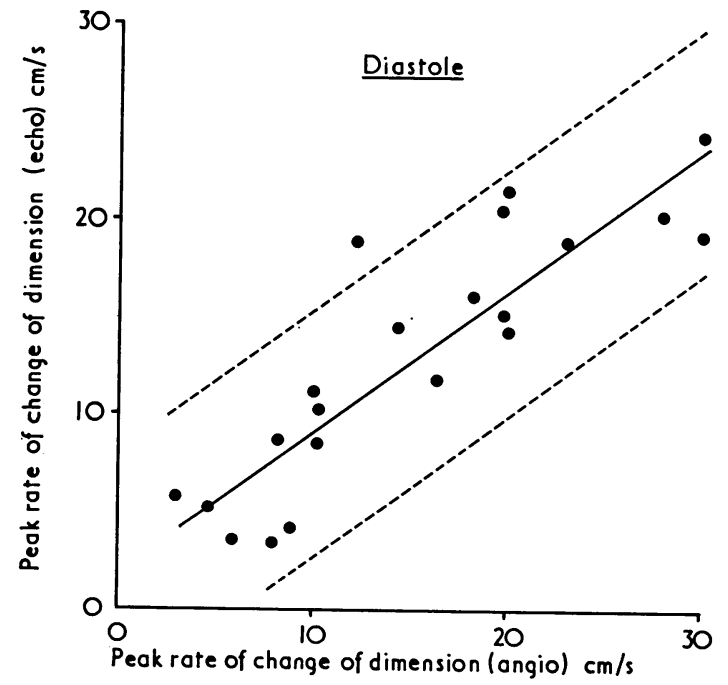

FIG. 6 Relation between estimates of peak diastolic rates of left ventricular wall movement made by echocardiography and angiography. 
response required to describe left ventricular wall movement in adults is $10 \mathrm{~Hz}$, so that cineangiograms at 50 frames/s are adequate for this purpose.

Both methods of measurement of peak rates of wall movement used in the present study have limitations. It has been demonstrated that the outer margin of the opacified left ventricular cavity at angiography does not necessarily represent the endocardial surface of the left ventricular wall (Mitchell, Wildenthal, and Mullins, 1969). This is particularly the case at endsystole, when the angiogram underestimates left ventricular volume, and so contributes to the consistently higher rates of wall movement observed in the present study using angiography. Filling defects caused by trabeculae and papillary muscles may lead to difficulty in defining the perimeter of the cavity during digitization, particularly at the apex of the ventricle at end-systole, but these are less prominent in the region immediately below the mitral valve and mid-systole and diastole where peak rates of wall movement occur. The position of the cursor used to reproduce the path of the ultrasound beam was to some extent arbitrary. Its placing depended on the echocardiographic observation that the dimension is immediately below the mitral valve (Feigenbaum, 1972), while previous comparisons with angiography have shown it to approximate to the minor axis of the left ventricular ellipsoid, and theoretical considerations suggest that maximum echoes are recorded when the ultrasound beam strikes a surface at right angles (Wells, 1969). A potential disadvantage of the echocardiographic method is sensitivity to variation in the direction taken by the ultrasound beam across the left ventricular cavity. The present study has shown that, with structures whose shape is that of an actual left ventricular cavity rather than an idealized geometrical figure, beam orientation does not appear to be critical, and changes over a range of $40^{\circ}$ are accompanied by only minor loss of reproducibility. This range is very much greater than that over which satisfactory echoes can be obtained probably because of the requirement that the ultrasound beam should strike both endocardial surfaces at right angles. The presence of reversed septal movement did not appear to influence agreement between the two methods, possibly because its presence is often associated with an increase in the amplitude of posterior wall movement.

There were also limitations in the design of the present study. Echocardiography and angiography cannot be performed simultaneously, and, though the time interval between the two measurements was reduced to a minimum, considerable beat-tobeat variation may have occurred, particularly in patients with atrial fibrillation. A second factor was that the same dimension was not measured by the two methods. The present investigation, however, confirms previous ones (Fortuin et al., 1971; Gibson, 1973) in showing the similarity in magnitude of the echocardiographic dimension with a comparable angiographic one in the posteroanterior or right anterior oblique projections. The primary indication in all patients for angiography was diagnostic, and it was not felt that this would have been served by a series of lateral angiograms. In spite of these factors, however, the agreement observed between peak rates of wall movement using these two different methods goes some way towards validating both in a situation where direct measurement is not possible, and suggests that either may be used to study ventricular wall movement in the clinical context.

\section{References}

Chapelle, M., and Mensch, B. (1969). Etude des variations du diametre ventriculaire gauche chez l'homme par échocardiographie transthoracique. Archives des Maladies $d u$ Coeur et des Vaisseaux, 62, 1505.

Diamond, M. A., Dillon, J. C., Haine, C. L., Chang, S., and Feigenbaum, H. (I97I). Echocardiographic features of atrial septal defect. Circulation, 43, I29.

Feigenbaum, H. (1972). Echocardiography. Lea and Febiger, Philadelphia.

Feigenbaum, H., Wolfe, S. B., Popp, R. L., Haine, C. L., and Dodge, H. T. (1969). Correlation of ultrasound with angiocardiography in measuring left ventricular diastolic volume (abstract). American fournal of Cardiology, 23, I I I.

Fortuin, N. J., Hood, W. P., Sherman, M. E., and Craige, E. (1971). Determination of left ventricular volumes by ultrasound. Circulation, 44, 575.

Gault, J. H., Ross, J., Jr., and Braunwald, E. (1968). Contractile state of the left ventricle in man. Instantaneous tension-velocity-length relations in patients with and without disease of the left ventricular myocardium. Circulation Research, 22, 45I.

Gibson, D. G. (1973). Estimation of left ventricular size by echocardiography. British Heart fournal, 35, I28.

Gibson, D. G., and Brown, D. (1973). Measurement of instantaneous left ventricular dimension and filling rate in man, using echocardiography. British Heart fournal, 35, II4I.

Griffith, J. M., and Henry, W. L. (1973). Video scanneranalog computer system for semi-automatic analysis of routine echocardiograms. American fournal of Cardiology, 32, $96 \mathrm{r}$.

Miller, H. C., Gibson, D. G., and Stephens, J. D. (1973). Role of echocardiography and phonocardiography in the diagnosis of mitral paraprosthetic regurgitation with Starr-Edwards prostheses. British Heart fournal, 35, 1217.

Mitchell, J. H., Wildenthal, K., and Mullins, C. B. (1969). Geometrical studies of the left ventricle utilizing biplane cinefluorography. Federation Proceedings, 28, 1334.

Wells, P. N. T. (1969). Physical Principles of Ultrasonic Diagnosis. Academic Press, London and New York.

Requests for reprints to Dr. Derek Gibson, Cardiac Department, Brompton Hospital, Fulham Road, London $\mathrm{SW}_{3}$ 6HP. 